\title{
Effect of family-oriented interviews on family function of young persons attending the family practice clinic in Oauthc, lle Ife, south-western Nigeria
}

\author{
Akinjide Olurotimi Ogundokuna*, Emmanuel Akintunde Abioye-Kuteyia , Ibrahim Sebutu Belloa (iD, \\ Olanrewaju Oloyede Oyegbade ${ }^{a}$ (D), Samuel Aanu Olowookere ${ }^{a}$ and Akintunde Julius Olowookere ${ }^{a}$
}

aObafemi Awolowo University Teaching Hospitals Complex, Ile Ife, Nigeria

*Corresponding author, email: akinjideogundokun@gmail.com

The outcome of a young person's future is affected by the support received from the family. Support that is received is related to the quality of family functioning of the young person. Family-oriented interview assesses the family of a patient who presents for consultation, through the patient. It diagnoses relationship issues in a family and helps in solving them. It may be best suited for the young-person encounter in a clinic as it ensures privacy, an important requirement for young-person care. The study objective was to assess the perceived family function of young persons and the perceived effect on this of family-oriented interview. The study had a quasi-experimental, pre- and post-test design, and the setting was in the family medicine clinic. Family-oriented interview was conducted for 221 young persons after an initial family function assessment. They were each followed up for 12 weeks and family function was reassessed. Perceived family function was significantly associated with very close relationships with the family members, especially fathers and mothers. Family-oriented interview may have significantly improved perceived family function in the study. Family-oriented interview of young persons presenting for medical care is recommended.

Keywords: family, family-oriented interview, perceived family function, young persons

\begin{abstract}
Background
A family is a group of people affiliated by consanguinity, affinity, or co-residence. It can also be described as a basic social unit consisting of parents and their children, whether dwelling together or not. A properly functioning family will have good intra-family relationships and thereby give optimum support to its members leading to better adaptation. ${ }^{1,2}$ Also, a functioning family will have good parental monitoring and supervision, and prevent association of a young person with deviant peers, which is a primary pathway leading to onset and escalation of high-risk behaviour in young persons. ${ }^{3}$ Young persons who live with two parents-biological, step-parents, or any combination thereofare observed to be significantly less likely to engage in risky behaviours such as smoking, property damage, illegal drug use, or running away from home. ${ }^{3}$
\end{abstract}

Family dysfunction has been linked to early onset of depression in young people. ${ }^{4,5}$ The effects of family dysfunction can continue into adulthood. Families characterised by conflict and aggression and by relationships that are cold, unsupportive and neglectful place children at risk for a wide variety of emotional and behavioural problems and health-risk behaviours. ${ }^{6}$

As regards family interview, the most commonly used of the methods is the family-oriented interview. ${ }^{7}$ Family-oriented interview assesses the family of a patient who presents for consultation, through the patient. It diagnoses relationship issues in a family and helps in solving them. Young people desire confidentiality and trust from the physician in order to fully express their worries, therefore the family-oriented interview serves as an apt method of family interview. The method consists of family-oriented questions that have been found to have the ability to metaphorically bring the family into the consulting room and bring a family context to the presenting problem. ${ }^{8}$ It also involves the use of family genogram, which has been described as the simplest and most efficient method for understanding the family context of a patient encounter during a consultation. ${ }^{9}$ The next phase of interviewing can be a family meeting with a relative of the patient, or, furthermore, a family conference, to resolve complex issues within a family.

\section{Methodology}

The study was conducted in the family practice clinic of Obafemi Awolowo University Teaching Hospital, Ile Ife. The method was a quasi-experimental, pre- and post-test study design. Randomisation was not done because family-oriented interview has been proved to be beneficial in family practice, so respondents were all interviewed. A total of 221 young persons were recruited into the study after obtaining written informed consents from respondents, and parental assent from parents of respondents who were younger than 18 years.

The patients received routine care for the presenting ailment before study questionnaires were administered. The questionnaires were interviewer administered. Perceived family function was assessed in all participants using the family APGAR scale. $^{5}$

Respondents had a family-oriented interview at the beginning of the study and this was repeated after four weeks. Reassessment of perceived family function with the family APGAR scale was done 12 weeks later.

There were five family-oriented interview questions. These helped to assess the role of the family of the patient in respect of the presenting complaint. They were structured as follows. (1) Family history - has anyone else in the family had this symptom/ problem before? (2) What do your family members believe caused the problem and how should it be treated? (3) Who in the family is most concerned about this problem? (4) Along with your symptom, have there been any other recent changes or stresses in your life or family? (5) Can your family or friends be 
helpful to you in dealing with this problem? These were assessed with the genogram, which depicted the structure of the family, identifying relationship strengths and weaknesses between the patient and family members. Counselling was undertaken to discern what was responsible for relationship strain, if there was any, and solutions to such were agreed with the patient. Relationship strengths in the family were also reinforced.

The study period lasted 18 weeks as respondents were recruited in the first 6 weeks and were each followed up for 12 weeks. Ethical clearance was obtained from the ethics and research committee of the Obafemi Awolowo University Teaching Hospitals' Complex, Ile Ife.

There was no conflict of interest as regards the study. Sponsorship was by the authors and a grant from Obafemi Awolowo University Teaching Hospitals Complex, Ile-Ife.

Data entry and analysis were done using the SPSS package Version $16^{\circledR}$ (SPSS Inc, Chicago, IL, USA). Family function was classified as highly functional (APGAR scores of 7-10), moderately dysfunctional (APGAR scores of 4-6), and severely dysfunctional (APGAR scores of $0-3) .^{10}$ These categories were further grouped into functional (APGAR scores 7-10) and dysfunctional (APGAR scores $0-6) .{ }^{11}$ The correlates of perceived family function among the respondents were identified at the bivariate level using Pearson's chi-square and significant factors were included in a multiple logistic regression model to identify determinants of perceived family function. Family relationship patterns were generated from the genogram and categorised as very close and not very close. This was generated for the relationship between the respondents and their parents and siblings. Association between the family function, i.e. functional or dysfunctional, and family relationship patterns from the genogram was assessed using Pearson's chi-square.

The perceived effect of family-oriented interviews on family function was assessed by comparing family APGAR scores at weeks 1 and 2 using a paired sample t-test. The level of statistical significance was determined at $p<0.05$.

\section{Results}

\section{Socio-demographic characteristics of respondents}

A total of 213 respondents representing $96.4 \%$ of the respondents was available for assessment at the 12th week with the family APGAR scale. Socio-demographic characteristics of the respondents are illustrated in Table 1 . The mean age of the respondents was $20.2 \pm 2.6$ years. The age range was between 15 years and 24 years. Persons aged $20-24$ years constituted the majority of the participants (61.5\%). The male to female ratio (M:F) was 1:1.76. Most of the respondents belonged to the class II socio-economic class.

\section{Family types and composition of respondents}

The majority (84.2\%) of the parents of the respondents were in a form of marital union; more of the respondents belonged to the monogamous family type (63.8\%). The majority of the respondents had between one and three siblings (53.4\%).

\section{Perceived family function of respondents}

Most of the respondents (82.8\%) perceived their families as highly functional on the family APGAR scale (Figure 1). Among respondents whose parents were in a marital union, a higher
Table 1: Frequency distribution of respondents by socio-demographic characteristics

\begin{tabular}{lc}
\hline Socio-demographic characteristics & $\boldsymbol{n}(\%)$ \\
\hline Age in years $(n=221)$ & $85(38.5)$ \\
\hline $15-19$ & $136(61.5)$ \\
\hline $20-24$ & \\
\hline Sex ( $n=221)$ & $80(36.2)$ \\
\hline Male & $141(63.8)$ \\
\hline Female & \\
\hline Religion ( $n=221)$ & $189(85.5)$ \\
\hline Christianity & $32(14.5)$ \\
\hline Islam & \\
\hline Education $(n=221)$ & $109(49.3)$ \\
\hline Secondary & $112(50.7)$ \\
\hline Tertiary & \\
\hline Employment ( $n=221)$ & $12(5.4)$ \\
\hline Employed & $209(94.6)$ \\
\hline Unemployed & $29(13.2)$ \\
\hline Socio-economic classification $(n=219)^{*}$ & $98(44.8)$ \\
\hline Class I & $50(22.8)$ \\
\hline Class II & \\
\hline Class III & \\
\hline Class IV & \\
\hline Class V & \\
\hline To respond)
\end{tabular}

*Two respondents were orphans and were not captured by the Oyedeji et al. criteria.

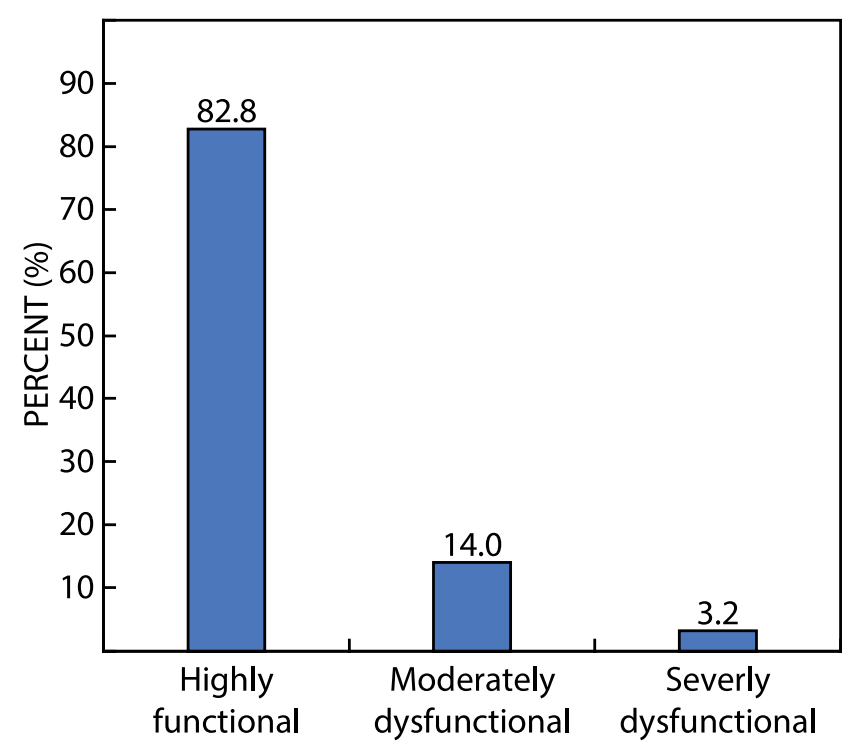

Figure 1: Perceived family function of respondents.

proportion of respondents from monogamous compared with polygamous families perceived their families as functional $(87.2 \%$ versus $73.3 \%)$. This relationship was statistically significant ( $p=0.027$ ) (Table 2). A significantly higher proportion of respondents who were very close to their fathers, mothers and siblings, compared with those who were not, perceived their families as functional $(p<0.05)$ (Table 3 ). 
Table 2: Relationship between family function and family type

\begin{tabular}{|c|c|c|c|c|}
\hline \multirow[t]{2}{*}{ Family type } & \multicolumn{2}{|c|}{ Perceived family function } & \multicolumn{2}{|c|}{ Statistic } \\
\hline & $\begin{array}{c}\text { Functional } \\
\qquad n(\%)\end{array}$ & $\begin{array}{c}\text { Dysfunctional } \\
\qquad n(\%)\end{array}$ & $\begin{array}{c}\text { Pearson's } \\
\chi^{2 *}\end{array}$ & $p$ \\
\hline Monogamous & $123(87.2)$ & $18(12.8)$ & \multirow{2}{*}{4.873} & \multirow{2}{*}{$0.027^{* *}$} \\
\hline Polygamous & $33(73.3)$ & $12(26.7)$ & & \\
\hline Single parent & $27(77.1)$ & $8(22.9)$ & \multirow{2}{*}{0.937} & \multirow{2}{*}{0.333} \\
\hline Both parents & $156(83.9)$ & $30(16.1)$ & & \\
\hline
\end{tabular}

Table 3: Relationship between perceived family function and relationship with family members

\begin{tabular}{|c|c|c|c|c|}
\hline \multirow[t]{2}{*}{ Relationship } & \multicolumn{2}{|c|}{ Family function } & \multicolumn{2}{|c|}{ Statistic } \\
\hline & $\begin{array}{c}\text { Functional } \\
n(\%)\end{array}$ & $\begin{array}{c}\text { Dysfunctional } \\
\qquad(\%)\end{array}$ & $\begin{array}{c}\text { Pearson's } \\
\chi^{2 *}\end{array}$ & $p$ \\
\hline \multicolumn{5}{|l|}{ With father } \\
\hline Very close & 87 (91.6) & $8(8.4)$ & \multirow{2}{*}{8.754} & \multirow{2}{*}{$0.003^{* *}$} \\
\hline Not very close & $79(76.0)$ & $25(24.0)$ & & \\
\hline \multicolumn{5}{|l|}{ With mother } \\
\hline Very close & $138(86.8)$ & $21(13.2)$ & \multirow{2}{*}{5.328} & \multirow{2}{*}{$0.021^{* *}$} \\
\hline Not very close & $38(73.1)$ & $14(26.9)$ & & \\
\hline \multicolumn{5}{|l|}{ With siblings } \\
\hline Very close & $149(85.1)$ & $26(14.9)$ & \multirow{2}{*}{3.862} & \multirow{2}{*}{$0.049^{* *}$} \\
\hline Not very close & $25(71.4)$ & $10(28.6)$ & & \\
\hline
\end{tabular}

*df $=1$.

**Significant, $n=$ number.

Table 4: Paired t-test comparing weeks 1 and 12 APGAR scores in the study population

\begin{tabular}{lccccc}
\hline Factor & Mean & $\begin{array}{c}\text { Standard } \\
\text { deviation }\end{array}$ & $\boldsymbol{n}$ & $\mathbf{t}(\mathbf{d f})$ & $\boldsymbol{p}$ \\
\hline $\begin{array}{l}\text { Week one } \\
\text { APGAR scores }\end{array}$ & 7.820 & 1.715 & 213 & & \\
$\begin{array}{l}\text { Week twelve } \\
\text { APGAR scores }\end{array}$ & 8.160 & 1.376 & 213 & $6.292(212)$ & $<0.001$ \\
$\begin{array}{l}\text { Difference in } \\
\text { mean }\end{array}$ & 0.343 & 0.795 & & & \\
\hline
\end{tabular}

\section{Perceived effect of family-oriented interviews on family function}

There was a significant difference in mean APGAR scores between week 1 and week 12; this may suggest an effect of family-oriented interview on perceived family function in the study (Table 4).

\section{Discussion}

The challenges of family dysfunction are numerous and have farreaching consequences on the development of young persons. Products of dysfunctional families are also likely to start dysfunctional families if they are not promptly identified and managed. The current study suggests that there exists an effect of family-oriented interview on perceived family function of young persons attending a family practice clinic. The majority
$(82.8 \%)$ of the respondents in the study perceived their families as functional at the week one APGAR assessment; this proportion may be due to strong family interactions and support as noted in the African family structure as alluded to in another study. ${ }^{11}$

Socio-demographic factors did not influence family function. However, in contrast to the findings of a very high proportion of respondents from lower social classes perceiving their families as dysfunctional in another study, ${ }_{1}^{11}$ the proportion of respondents who perceived their families as functional were higher than those who did not, for both higher and lower social classes. The gender distribution in this study was predominantly female, different from what was observed in a study in a similar age group ${ }^{12}$ where about equal proportions of males and females were seen. This may be because the study was hospital based and patients were recruited serially into the study as they registered for care and met the inclusion criteria.

Among respondents whose parents were in a marital union, respondents from monogamous families were significantly more likely to perceive their families as functional than those from polygamous families. The effect of the type of family a young person belongs to on the future outcome of such a young person cannot be underrated. In a study to assess the impact of family type on secondary school students' academic performance, the participants from monogamous families performed significantly better than those from polygamous and single-parent families. ${ }^{13}$ This was not different from what was observed in another setting where in a study to assess the effect of family structure and parenthood on the academic performance of some university students, a significant difference was found between the academic performance of students from a single-parent family and those from a two-parent family structure, with those from the two-parent families doing better. ${ }^{14}$ The reason adduced for these findings was that children brought up in monogamous families were usually more emotionally stable and they suffer less emotional trauma and therefore have good self-esteem. ${ }^{15}$ Good self-esteem has been linked with good family function in students, ${ }^{16}$ which in turn contributes to their educational development. Also, being from a polygamous family has been associated with increased occurrence of sexual activities. ${ }^{12}$

Very close relationships with family members significantly affected the perception of the families of young persons in the study. The importance of relationship with parents to the development of a young person cannot be overemphasised. Low levels of connection between the young person and both parents, low levels of regulation from the mother, as well as high levels of psychological control from both parents and a large amount of parent-child conflict, have been associated significantly with suicide ideation in a study by van Renen and Wild..$^{15}$ In another study, high levels of parent-child conflict and low levels of father-child connection appear to be the most important independent predictors of suicidal ideation or behaviour. ${ }^{14}$ Good parental relationships with a young person have similarly been linked with good social initiative, lower depression and lower antisocial behaviour. ${ }^{17}$

The importance of the bond existing between family members in the overall well-being of a young person is reflected in the fact that the quality of the mother-daughter relationship, for instance, influences the age at which teenage girls first engage in sex. ${ }^{18}$ This bond is a product of the trust between a parent and a young person who is then able to confide in the parent. 
Many behavioural characteristics have been related to healthy family functioning; a good relationship with parents has been found to help in weight-control studies where increasing levels of acceptance from parents, particularly fathers, during a familybased weight control intervention was correlated with increased child weight loss. ${ }^{19}$ Good family functioning has been significantly correlated with good self-esteem of young people with good parental relationships. ${ }^{16}$

There was a significant perceived effect of family-oriented interview on the family function of the respondents in the study. Family-oriented interview, when adopted with patients, has been associated with high satisfaction of the patients with their physicians..$^{20}$ This was because the patients appreciated the depth of the enquiry into their families. ${ }^{20}$ Also, family-oriented interview had been described as being able to metaphorically bring the family into the consulting room, ${ }^{7}$ which can form the platform for resolving family relationship challenges the patient may have with his/her family members, leading to better satisfaction. A good family assessment, as exemplified by the family-oriented interview, has been described as having therapeutic ability by itself even without further family intervention. It is suggested that such an assessment be incorporated into routine clinical care. ${ }^{21}$

There was difference in mean across the study population, which was statistically significant. The finding suggests that familyoriented interview, like other family interventions, has the potential to solve family issues., 822 The outcome of the study therefore suggests that using family-oriented interview in the management of young persons may help to identify and address family dysfunction in their families.

\section{Limitations}

The information in the study was obtained by self-reporting; therefore it is possible that certain information may be exaggerated or withheld by respondents. Also, sampling in this study was not by a randomised sampling method, thus selection bias may be present causing skewed results. These are considered as factors that may be limitations for the study.

\section{References}

1. Bray JH, Campbell TL. The family's influence on health. In: Rakel RE, editor. Textbook of family medicine. 7th ed. Philadephia: Saunders Elsevier; 2007. p. 325-34.

2. Ahmed SM, Lemkau JP. Psychosocial influence on health. In: Rakel RE, editor. Textbook of family medicine. 7th ed. Philadephia: Saunders Elsevier; 2007. p. 35-41.

3. Overturf JV, Downs B. Adolescent behavior and family relationships. Proceedings of the annual meeting of the population association of America, Minneapolis; 2003 May 1-3 [cited 2012 May 25]. Available from http://www.populationassociation.org.

4. Shanahan L, Copeland WE, Costello EJ. Child-, adolescent- and young adult-onset depressions: differential risk factors in development? Psycho Med. 2011;41(11):2265-74. http://dx.doi.org/10.1017/ S0033291711000675
5. Adewuya AO, Ologun $\mathrm{YA}$. Factors associated with depressive symptoms in Nigerian adolescents. J Adolesc Health. 2006;39(1):10510. http://dx.doi.org/10.1016/j.jadohealth.2005.08.016

6. Repetti RL, Taylor SE, Seeman TE. Risky families: Family social environments and the mental and physical health of offspring. Psychol Bull. 2002;128:330-66. http://dx.doi.org/10.1037/00332909.128.2.330

7. Cole-kelly K, Seaburn DB, Campbell TL, McDaniel SH, Hepworth J, Lorenz A. A family-oriented approach to individual patients. In: Family-oriented primary care. 2nd ed. New York: Springer; 2005. p. 43-53.

8. Campbell TL, McDaniel SH, Cole-Kelly K, et al. Family interviewing: a review of the literature in primary care. Fam Med. 2002;34(5):312-8.

9. McDaniel SH, Campbell TL, Hepworth J, et al. Family systems concepts: Tools for assessing families in primary care. In: Familyoriented primary care. 2nd ed. New York: Springer; 2005. p. 28-40.

10. Blitz-Lindeque J. How to assess family function. In: Mash B, BlitzLindeque J, editors. South African family practice manual. 2nd ed. Pretoria: Van Schaik; 2006. p 384.

11. Muyibi A, Ajayi I, Irabor A, et al. Relationship between adolescents' family function with socio demographic characteristics and behavior risk factors in a primary care facility. Afr J Prim Health Care Fam Med. 2010;2(1):1-7.

12. Olugbenga-Bello Al, Adebimpe WO, Abodunrin OL. Sexual risk behaviour among in-school adolescents in public secondary schools in a southwestern city in Nigeria. Int J Health Res. 2009;2(3):243-51.

13. Akomolafe MJ, Olorunfemi-olabisi FA. Impact of family type on secondary school students' academic performance in Ondo State, Nigeria. Eur J Edu Studies. 2011;3(3):481-7.

14. Uwaifo VO. The effects of family structure and parenthood on the academic performance of Nigerian University students. Stud Home Comm Sci. 2008;2(2):121-4.

15. van Renen LJ, Wild LG. Family functioning and suicidal ideation/ behaviour in adolescents: a pilot study. J Child Adolesc Ment Health. 2008;20(2):111-21. http://dx.doi.org/10.2989/ JCAMH.2008.20.2.7.690

16. Lian TC, Yusooff F. The effects of family functioning on self-esteem of children. Eur J Soc Sci. 2009;4(9):643-50.

17. Amoateng AY, Barber BK, Erickson LD. Family predictors of adolescent substance use: the case of high school students in the Cape Metropolitan Area, Cape Town, South Africa. J Child Adoles Ment Health.2006;18:7-15.http://dx.doi.org/10.2989/17280580609486612

18. Igwe WC, Ojinnaka N, Ejiofor SO, et al. Socio-demographic correlates of psychoactive substance abuse among secondary school students in Enugu, Nigeria. Eur J Soc Sci. 2009;12(2):277-83.

19. Stein Rl, Epstein LH, Raynor HA, et al. The influence of parenting change on pediatric weight control. Obesity Res. 2005;13:1749-55. http://dx.doi.org/10.1038/oby.2005.213

20. Medalie JH, Zyzanski SJ, Goodwin MA, et al. Two physician styles of focusing on the family. J Fam Pract. 2000 Mar;49(3):209-15.

21. Keitner GI. Family assessment in the medical setting. In: Fava GA, Sonino N, Wise TN, editors. The psychosomatic assessment. Strategies to improve clinical practice. Basel: Karger; 2012. p. 203-22.

22. Campbell TL. The effectiveness of family interventions for physical disorders. J Marital Fam Ther. 2003;29(2):263-81. http://dx.doi.org/10.1111/j.1752-0606.2003.tb01204.x

Received: 27-07-2016 Accepted: 01-10-2016 